Brazilian Journal
of Chemical
Engineering

ISSN 0104-6632

Printed in Brazil

www.abeq.org.br/bjche

Vol. 33, No. 01, pp. 105 - 114, January - March, 2016

dx.doi.org/10.1590/0104-6632.20160331s20140078

\title{
LEACHING OF COARSE CALICHE ORE. EXPERIMENT AND MODELLING
}

\author{
S. Valdez ${ }^{1}$, J. I. Ordóñez ${ }^{1 *}$, L. A. Cisternas ${ }^{1,3}$ and L. Moreno ${ }^{1,2}$ \\ ${ }^{1}$ Department of Chemical and Mineral Process Engineering, Universidad de Antofagasta, Chile. \\ E-mail: javier.ordonez@uantof.cl \\ ${ }^{2}$ Department of Chemical Engineering and Technology, Royal Institute of Technology, Sweden. \\ ${ }^{3}$ Centro de Investigación Científico y Tecnológico para la Minería, Chile.
}

(Submitted: September 25, 2014 ; Revised: March 11, 2015 ; Accepted: March 15, 2015)

\begin{abstract}
Heap leaching of caliche ores is frequently performed with run-of-mine (ROM) material, which includes rocks of very different sizes; however, most of the experimental data are obtained using small particles. To contribute to the understanding of caliche leaching, an experiment using coarse particles was carried out. The recoveries obtained from this experiment were compared with those observed in the leaching of fine particles and, as expected, a larger volume of leachant was required for leaching coarse particles to reach the same recovery. For the highly soluble species nitrate, the recovery was modelled using a previously developed model, obtaining good agreement without any fitting by using only the mass transfer coefficient obtained, by fitting, from fine particle leaching data in previous works. Physical properties such as permeability and capillarity were determined, showing that capillary forces are large, but that the permeability is very small, implying that flow through caliche particles should be very small.

Keywords: Nitrate; Physical properties; Column leaching; Particle size effect; Phenomenological model.
\end{abstract}

\section{INTRODUCTION}

Caliche is a mineral composed of a high proportion of water-soluble species that is naturally found in northern Chile, in the regions of Tarapacá and Antofagasta. The most important products obtained from this mineral are nitrates and iodine. Natural nitrates (also named Saltpetre) are used for the manufacture of fertilizers and as industrial salts, while iodine is employed in medical and technological applications (Gálvez et al., 2012; Valencia et al., 2008; Ericksen, 1983). Chile is the world's largest producer of iodine and natural nitrates (USGS, 2013).

The recovery of metals and non-metals from minerals using aqueous solutions has been carried out since ancient times, both vat and heap leaching being the most used techniques. In general, the leaching consists of the dissolution of solids or part of them by adding a leaching solution, which is subsequently conducted to a separation process (De Andrade Lima, 2004). In the case of the production of iodine and nitrates from caliche, depending on the grade and granulometry of the ore, the leaching process takes place in vats or heaps. The heap leaching has gained great importance due to the decreasing ore grades and the increment of processing costs (Ghorbani et al., 2011). Caliche heaps are frequently constructed by accumulation of 600 to 900 thousand tons of ROM caliche, which means that a wide spectrum of particle sizes composes the heaps.

Caliche heaps are irrigated at the top with water or recirculated solutions and the leachate obtained at the bottom is sent to the iodine extraction plant, where the iodate is transformed to metallic iodine. The remaining solution is afterwards conducted to evaporation ponds to obtain sodium nitrate and other

*To whom correspondence should be addressed 
salts (SQM, 2013; Wheeler, 2010).

For metallic minerals, such as copper ores, the leaching is governed by chemical reactions (Bouffard and Dixon, 2001; Bennett et al., 2012), whereas the leaching in caliche is determined by dissolution of the soluble species, which is governed by concentration differences. Another important difference with metallic minerals is that caliche has a high fraction of soluble minerals formed by different species that are dissolved simultaneously at different rates, which makes the modelling of caliche heap leaching a complex task (Gálvez et al., 2012). The high fraction of soluble species causes a gradual decrease in the size of the particles and, therefore, a diminution of the heap height.

Many factors affect the performance of heap leaching, such as the macro hydrodynamics of the heap, compaction, channelling, changing permeability and the particle size, among others. The last one has an important effect on the leaching since the magnitude of the radius has a direct relation with the resistance to mass transfer within the solid matrix and with the surface area of contact between leachant and solid (Ghorbani et al., 2011). In previous works (Ordóñez et al., 2013; Ordóñez et al., 2014), column leaching experiments on a pilot scale using fine material were performed and a phenomenological model based on mass balance was fitted with acceptable accuracy for the dissolution of the highly soluble species. In the present study, coarser particles were leached, in order to get empirical information somewhat closer to industrial conditions, where the particles can reach up to several decimetres. Moreover, the phenomenological model was tested in a new column experiment, using the same mass transfer coefficient, $k$, obtained by fitting in an experiment with small sized particles.

One of the possible causes for poor performance of heap leaching could be the inadequate understanding of the mineralogy and the physical properties related to it. Therefore, experiments were also done to characterize the material physically, such as permeability and capillary suction tests.

\section{METHODOLOGY}

\section{Caliche and Solutions}

The particles of caliche used in the column experiment and in the physical characterization tests were obtained from Northern Chile. The soluble fraction of the mineral was chemically analysed and its composition is shown in Table 1. Nitrate was determined by molecular absorption spectroscopy (UV2, Unicam UV/Vis). Sulphate was quantified by gravimetry, while sodium, potassium, magnesium and calcium were measured by atomic absorption spectroscopy (220FS, Varian). Acid-base volumetry was used for boron determination. Chloride and iodine were determined by titration with silver nitrate and sodium thiosulphate, respectively. For perchlorate analysis, a selective ion-electrode was used (Cole Parmer).

Table 1: Composition of soluble species in the caliche. Concentration in $\mathbf{w t} \%$.

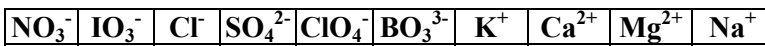

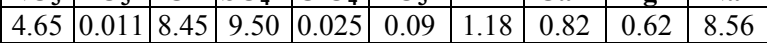

According to mineralogical XRD analysis (Siemens D5000 Diffractometer), the most abundant water-soluble species in the caliche ore used is Halite $(\mathrm{NaCl})$, which is the unique source of chloride; meanwhile, nitrate is shared between Humberstonite $\left(\mathrm{K}_{3} \mathrm{Na}_{7} \mathrm{Mg}_{2}\left(\mathrm{SO}_{4}\right)_{6}\left(\mathrm{NO}_{3}\right)_{2} \cdot 6 \mathrm{H}_{2} \mathrm{O}\right)$ and Nitratine $\left(\mathrm{NaNO}_{3}\right)$, both very soluble minerals. Sulphate is widely spread in caliche and it is associated with sodium, potassium, magnesium and calcium. The insoluble species are present as silicates such as Quartz $\left(\mathrm{SiO}_{2}\right)$ and Albite $\left(\mathrm{NaAlSi}_{3} \mathrm{O}_{8}\right)$. The semi-analytical quantification by XRD of the species is listed in Table 2.

Table 2: Main mineral composition of caliche determined by XRD.

\begin{tabular}{|l|l|r|}
\hline Mineral & Formula & wt\% \\
\hline Halite & $\mathrm{NaCl}$ & 28.2 \\
Quartz & $\mathrm{SiO}_{2}$ & 17.8 \\
Albite & $\mathrm{NaAlSi}_{3} \mathrm{O}_{8}$ & 16.2 \\
Humberstonite & $\mathrm{K}_{3} \mathrm{Na}_{7} \mathrm{Mg}_{2}\left(\mathrm{SO}_{4}\right)_{6}\left(\mathrm{NO}_{3}\right)_{2} \cdot 6 \mathrm{H}_{2} \mathrm{O}$ & 13.4 \\
Nitratine & $\mathrm{NaNO}_{3}$ & 8.1 \\
Loeweite & $\mathrm{Na}_{12} \mathrm{Mg}_{7}\left(\mathrm{SO}_{4}\right)_{13} \cdot 15 \mathrm{H}_{2} \mathrm{O}$ & 3.4 \\
Glauberite & $\mathrm{Na}_{2} \mathrm{Ca}\left(\mathrm{SO}_{4}\right)_{2}$ & 3.6 \\
Orthoclase & $\mathrm{KAlSi} \mathrm{O}_{8}$ & 7.1 \\
Polyhalite & $\mathrm{K}_{2} \mathrm{Ca}_{2} \mathrm{Mg}\left(\mathrm{SO}_{4}\right)_{4} \cdot 2 \mathrm{H}_{2} \mathrm{O}$ & 2.2 \\
\hline
\end{tabular}

In the leaching test, rocks with masses ranging from 0.2 to $4.3 \mathrm{~kg}$ were placed into the column. For the granulometric characterization, the volume-weighted particle radius was used, which was $6 \mathrm{~cm}$. The mass distribution is presented in Figure 1, where $40 \%$ of the total loaded mass is found in the last interval, in which particles with masses larger than $3.2 \mathrm{~kg}$ are included.

The column employed for leaching was constructed with acrylic, with a square base of $28 \mathrm{~cm}$-side and a height of $80 \mathrm{~cm}$. Rocks of caliche of different sizes 
were loaded in the column; some of them were flattened on one side and attached to the walls using silicone on the upper part of the perimeter to avoid direct liquid flow between the caliche rock and the column wall. The total mass of caliche loaded in the column was $28.5 \mathrm{~kg}$. The void spaces were filled with inert glass particles (Figure 2). For the column leaching experiment, the solution employed to leach caliche was demineralised water, which was uniformly distributed.

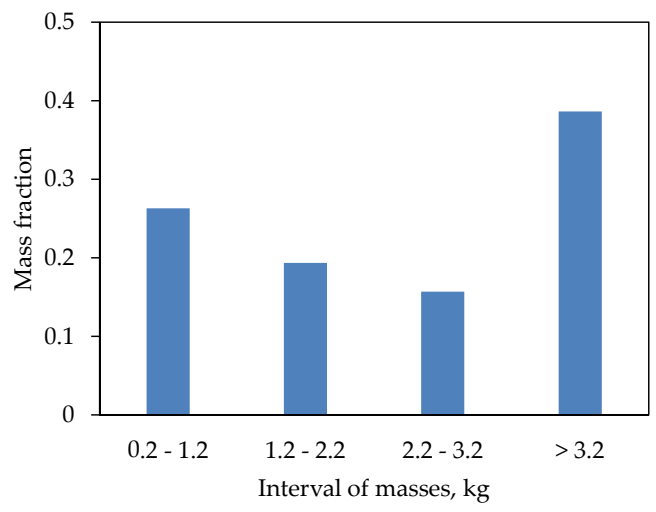

Figure 1: Particle mass distribution of caliche loaded in the column leaching experiment. Column leaching experiments.

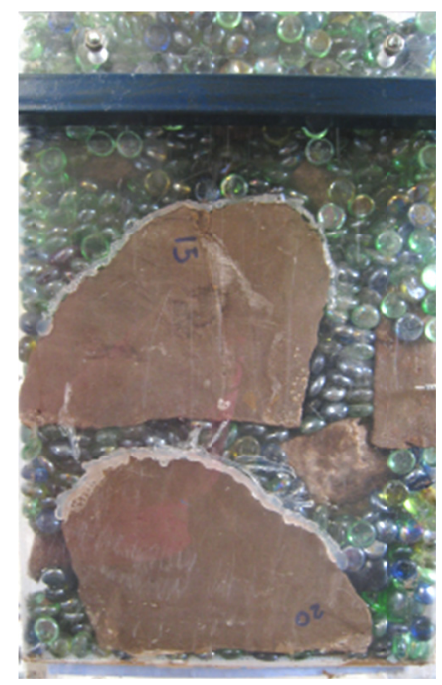

Figure 2: Column leaching experiment with large particles. Two large particles attached to the column walls are shown.

The leaching was performed with an initial irrigation rate of $4 \mathrm{~L} / \mathrm{h} / \mathrm{m}^{2}$, which was reduced to half after $600 \mathrm{~h}$. The leaching was performed with an intermittent irrigation regime of 8 hours a day for a total period of 71 days. During this time, samples of liquid were taken every day and chemically analysed. When the leaching finalized, the column was dismantled and the remaining rocks were removed and weighed. Samples of residues were also analysed. The recovery of each ion is calculated considering the total mass of the ion that was removed by the leachant and the mass remaining in the residue.

\section{Physical Characterization of Caliche Ores}

Some physical properties of the mineral were determined, which included: a) capillary suction, b) apparent density, c) open porosity and d) permeability. They provide useful information on the phenomena associated with the mineral such as the wetting and the transport of leachant in the particle, which are fundamental to understand heap leaching. Since caliche is a predominantly water-soluble mineral, kerosene was used in the measurements in order to avoid the dissolution of caliche.

The capillary suction was determined in terms of the capillary coefficient $\left(k_{c}\right)$, which is defined as the mass of absorbed liquid per cross-sectional area and per square root of the elapsed time for liquid uptake. For determining the capillary suction, cube-shaped caliche rocks were put in contact with kerosene, maintaining an immersion depth of $3 \mathrm{~mm}$ at room temperature during 5 hours. The mass of the rocks with the suctioned liquid was determined along the time; in each measurement, the sample was rapidly removed from the support, weighed, and returned to the vessel according to the standard UNE-EN 1925 (AENOR, 1999). Since the test is done with kerosene, the obtained values were transformed in terms of water properties by using the ratios between the densities of kerosene and water. For determining the apparent density $(\rho)$, rocks of caliche with different sizes and previously weighed dry were submerged in a glass beaker filled with kerosene for a very short time to avoid the penetration of kerosene into the caliche pores. The apparent caliche density was calculated by dividing the mass of the dry sample by the volume of displaced kerosene $\left(V_{s}\right)$. This density is apparent since it includes the pores in the rock (open and closed pores).

To estimate the open porosity of the caliche $(\varepsilon)$ the rocks were dried and put in a desiccator that contained kerosene at the bottom. The air in the inner pores was removed using a vacuum pump for 2 hours. After that, the caliche was submerged in the kerosene, the vacuum pump was then stopped and 
the valve was opened to recover the atmospheric pressure in the desiccator. The mass of the caliche saturated in kerosene is then determined. The open porosity was calculated by Equation (1).

$\varepsilon=\frac{M_{s a t}-M_{s}}{V_{s} \rho_{k}}$

where $M_{\text {sat }}$ is the mass of the sample saturated in kerosene, $M_{s}$ the initial mass of the solid, $V_{s}$ the volume of sample and $\rho_{k}$ the density of kerosene.

Permeability $(K)$ is the capability of a porous material to permit the flow of fluids through its pore spaces. For the study of the permeability in the caliche, cubic samples with cross sectional area of about $50 \mathrm{~cm}^{2}$ were cut. The samples, with a hole of $1 \mathrm{~cm}$ of diameter vertically drilled in the centre, were saturated in vacuum with kerosene for 24 hours. The top and the bottom of the samples were sealed with silicone and adhered to acrylic plates. The plate on the sample top had a hole at the centre, through which kerosene was introduced into the caliche sample using a hose connected to the plate (Figure 3). The total height of the experiment from the solid sample to the level of the kerosene in the hose $(H)$ was about $3.5 \mathrm{~m}$.

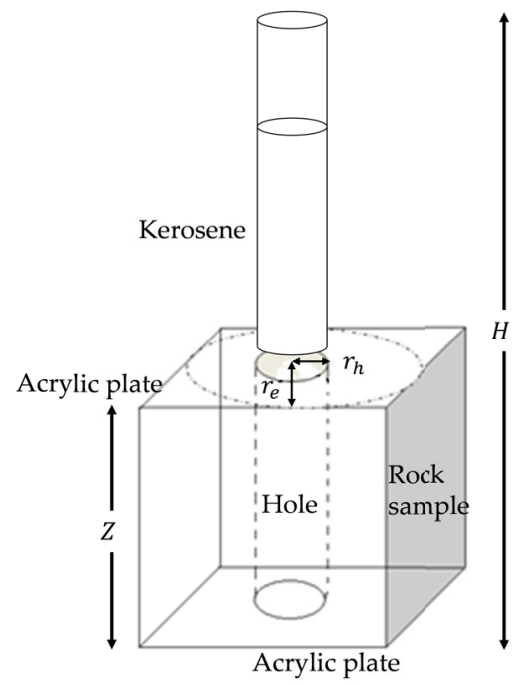

Figure 3: Layout of permeability test. $H=3.5 \mathrm{~m}$.

The variation of height level of kerosene in the hose was measured and used to calculate the permeability according to the Equation (2) (Bird et al., 2002).

$$
K=\frac{\ln \left(\frac{r_{e}}{r_{h}}\right) Q \mu}{\rho_{k} g h_{m} 2 \pi Z}
$$

where $r_{e}$ is the external radius of the sample, $r_{h}$ corresponds to the hole radius, $Q$ is the flow, $\mu$ is the dynamic viscosity of kerosene, $g$ is the gravity, $\rho_{k}$ is the kerosene density, $h_{m}$ corresponds to the average height of kerosene and $Z$ represents the height of the sample. As Equation (2) is formulated for cylindrical geometries and the samples used have cubic shapes, a weighted radius defined as $90 \%$ of the average radius was considered for $r_{e}$. This approach gave the best agreement for the different ratios $r_{e} / r_{h}$, which were tested by simulation.

\section{MODEL FUNDAMENTALS}

The model that was used in this work was described by Gálvez et al. (2012) and defines the dissolution of highly soluble species of caliche such as nitrate and iodine in terms of their outlet concentration. The model is 1-D and the column is represented by well-stirred reactors in series. It is assumed that the particles are spherical and of equal size, which decrease when the soluble species are dissolved.

According to the Brunner and Tolloczko model (Dokoumetzidis and Macheras, 2006), the variation of the particle radius $\left(r_{i}\right)$ with time is proportional to the difference between the solubility $\left(C_{S}\right)$ and concentration in the liquid $\left(C_{i}\right)$, where the proportionality factor is given by the mass transfer coefficient, $k$ (Equation (3)). The fraction of soluble material $(\alpha)$ and the mineral density $(\rho)$ are also considered.

$\frac{d r_{i}}{d t}=-\frac{k}{\alpha \rho}\left(C_{s}-C_{i}\right)$

Performing a material balance in each reactor, the concentration of the species along the heap may be calculated from Equation (4).

$\frac{d V_{w i} C_{i}}{d t}=q A\left(C_{i-1}-C_{i}\right)-N_{p} \alpha \rho 4 \pi r_{i}^{2} \frac{d r_{i}}{d t}$

where the accumulation in the reactor " $i$ ", represented by the left hand side term, is equal to the mass transported by advection between adjacent reactors and the dissolution from the particles. The term of dissolution is obtained considering Equation (3) and the number of particles contained in the reactor " $i$ " $\left(N_{p}\right)$. For a more detailed description of the model, please review Gálvez et al. (2012). Subsequently, the 
phenomenological model was validated with experimental data, according to the work of Ordóñez et al. (2013); by using column leaching experiments, the adjustable parameter $(k)$ was fitted. However, the tests were carried out with small particles. In the present work, using the same $k$ obtained in the cited reference, simulations were carried out and compared with the leaching experiments with coarser particles.

\section{RESULTS AND DISCUSSION}

\section{Physical Characterization}

The caliche studied contained interesting mineralogical details on its surface. Longitudinal cuts were performed in order to observe the inner parts of the sample. Although, the major part of caliche surfaces showed an apparently homogeneous texture, in some samples saline veins were identified, possibly Halite.
In other ones, the presence of microcrystals less than $1 \mathrm{~mm}$ was observed, which can arise through a local dissolution provoked by a prolonged exposition of the surface to environmental moisture (Figure 4).

The porosity of rocks and their densities were determined and the results are summarized in Table 3. The open porosity of the caliche ranges between $2.4 \%$ and $16.3 \%$, with an average value of $9.5 \%$ for the 14 analysed samples. The open porosities in the heap leaching performance are mainly related to the liquid retention in the heap. Regarding the density measurements, no big differences were observed; the average value was $2309 \mathrm{~kg} / \mathrm{m}^{3}$, ranging from 2102 to $2468 \mathrm{~kg} / \mathrm{m}^{3}$. Wheeler (2010) found densities of 1900 $\mathrm{kg} / \mathrm{m}^{3}$ for caliche ores; however, these values cannot be directly compared since they include intra-particle spaces and fractures, which diminish the density. A correlation between density and porosity was not observed, since the specimens of caliche used have high heterogeneity in their compositions.

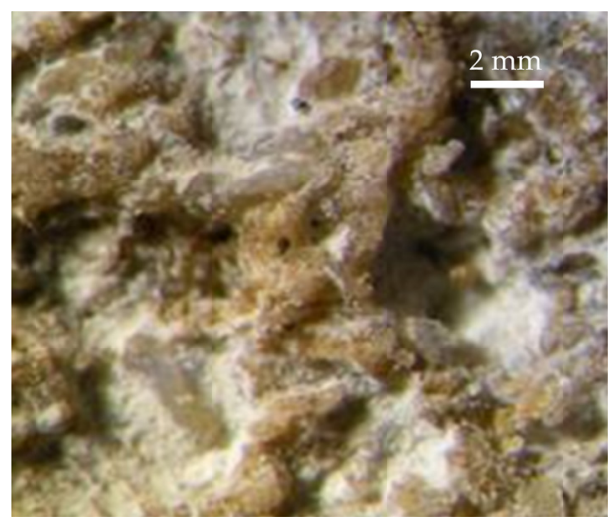

(a)

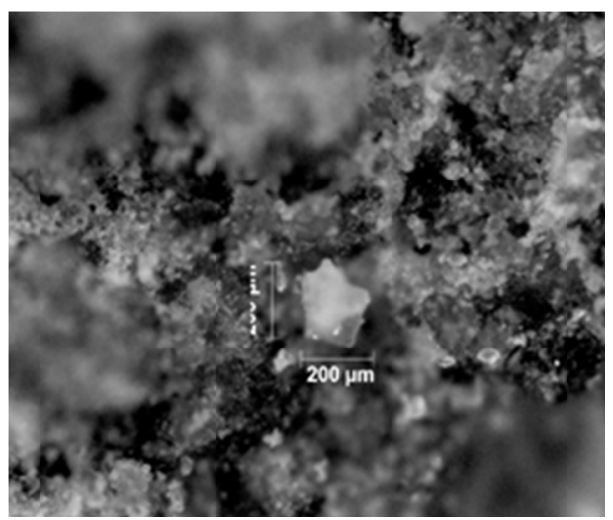

(b)

Figure 4: Detailed view of the surface of a caliche sample. (a) Saline veins (10X) and (b) Microcrystalline structure.

Table 3: Density and porosity determinations. Values correspond to the statistics for 14 samples. $(\mathrm{SD}=$ standard deviation).

\begin{tabular}{|c|c|c|}
\hline Entity & $\begin{array}{c}\text { Density, } \\
\mathrm{kg} / \mathrm{m}^{3}\end{array}$ & $\begin{array}{c}\text { Porosity, } \\
\%\end{array}$ \\
\hline Lowest value & 2102 & 2.4 \\
\hline Highest value & 2468 & 16.3 \\
\hline Average value & 2309 & 9.5 \\
\hline SD & 131 & 5.5 \\
\hline
\end{tabular}


When the particles are irrigated, two different regions are observed in the rocks: a water-saturated layer in the surface and a material slightly humid in the core of the rocks. This was observed in the laboratory in the capillarity tests and subsequently confirmed by the column experiment in the rocks attached to the column walls. Apparently the leaching solution flows on the particle surface and no liquid transport takes place through the inner part of the rock. The capillarity of caliche is large (Table 4) but the permeability is very small, about $5^{*} 10^{-17} \mathrm{~m}^{2}$ (Table 5). Therefore, the leaching agent would be transported into the particle by capillary forces, which are large when the material is dry, but they disappear once the material is humid. No water flow is expected through the caliche rocks due to the small permeability of the caliche. The leachant would flow along the surface of the caliche ores and water penetrates the inner part of the particles by capillary suction. From these data, it is possible to conclude that the pores in caliche are very small (large capillarity and small permeability) but they are abundant (no small porosity).

Table 4: Capillary absorption coefficients $\left(k_{c}\right)$ of caliche specimens. $(\mathrm{SD}=$ standard deviation $)$.

\begin{tabular}{l|l|l|l|l|l|l|l|l|l|l|l|} 
Sample & C1 & C2 & C3 & C4 & C5 & C6 & C7 & C8 & C9 & Mean & SD \\
\hline
\end{tabular} \begin{tabular}{|l|l|l|l|l|l|l|l|l|l|l|l|}
\hline$k_{c}, \mathrm{~kg} / \mathrm{m}^{2} / \mathrm{h}^{0.5}$ & 0.5 & 1.1 & 1.5 & 2.7 & 3.6 & 3.7 & 4.5 & 6.8 & 8.7 & $\mathbf{3 . 6}$ & $\mathbf{2 . 7}$ \\
\hline
\end{tabular}

Table 5: Permeability coefficient $(K)$ determined for caliche samples. (SD=standard deviation).

\begin{tabular}{|c|c|c|c|c|c|}
\hline Sample & P1 & P2 & P3 & Mean & SD \\
\hline$K, \mathrm{~m}^{2}$ & $7.4^{*} 10^{-18}$ & $5.7^{*} 10^{-17}$ & $8.1 * 10^{-17}$ & $\mathbf{4 . 9}^{*} \mathbf{1 0}^{-\mathbf{1 7}}$ & $\mathbf{3 . 8}^{*} \mathbf{1 0} \mathbf{1}^{-17}$ \\
\hline
\end{tabular}

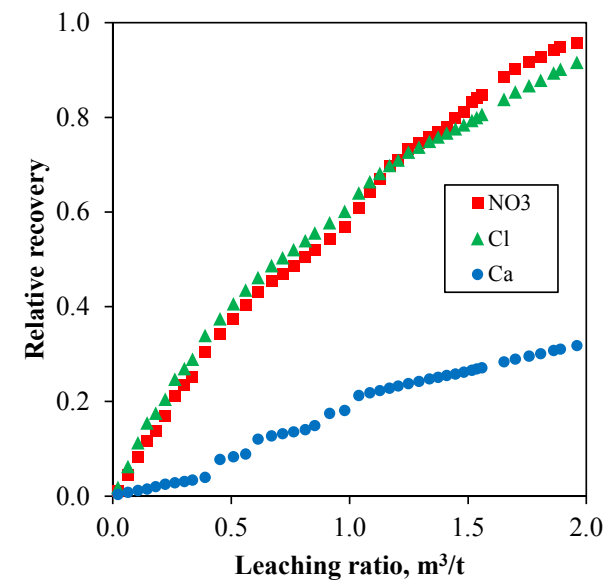

(a)

\section{Column Leaching Experiments}

Recovery of the ions was determined considering the mass of species extracted during leaching and that remaining in the residues. The composition of the residues is shown in Table 6. For nitrate, perchlorate and iodine the final recoveries were the highest, above $90 \%$. On the other hand, the species formed by calcium (Glauberite and Polyhalite) and boron were only partially leached, reaching recoveries of about $50 \%$ for these ions (Figure 5).

Table 6: Composition of the remaining soluble species in the residue after leaching. Concentration in $\mathrm{wt} \%$

\begin{tabular}{|c|c|c|c|c|c|c|c|c|c|}
\hline $\mathbf{N O}_{3}{ }^{-}$ & $\mathbf{I O}_{3}{ }^{-}$ & $\mathbf{C l}^{-}$ & $\mathbf{S O}_{4}{ }^{2-}$ & $\mathbf{C l O}_{4}{ }_{4}^{-}$ & $\mathbf{B O}_{3}{ }^{3-}$ & $\mathbf{K}^{+}$ & $\mathbf{C a}^{2+}$ & $\mathbf{M g}^{2+}$ & $\mathbf{N a}^{+}$ \\
\hline 0.35 & 0.001 & 1.10 & 2.80 & 0.003 & 0.07 & 0.19 & 0.69 & 0.15 & 0.86 \\
\hline
\end{tabular}

Significant increments in recovery were achieved up to $600 \mathrm{~h}$, which correspond to $1 \mathrm{~m}^{3} / \mathrm{t}$; after that, the extraction changed to slower kinetics due to a reduction by half of the irrigation rate. This is not visualized in Figure 5, since it shows the recovery as a function of the leaching ratio. In this case a small irrigation rate increases the slope of the curve. According to the recoveries, the volume of leachant used in the experiment was sufficient because the recoveries of ions were relatively high for the highly water-soluble species and even less soluble ions, such as sulphate, were close to $80 \%$. The use of glass stones may favour the channelling in the column and a part of the leachant may pass directly through the column without being effectively used for leaching.

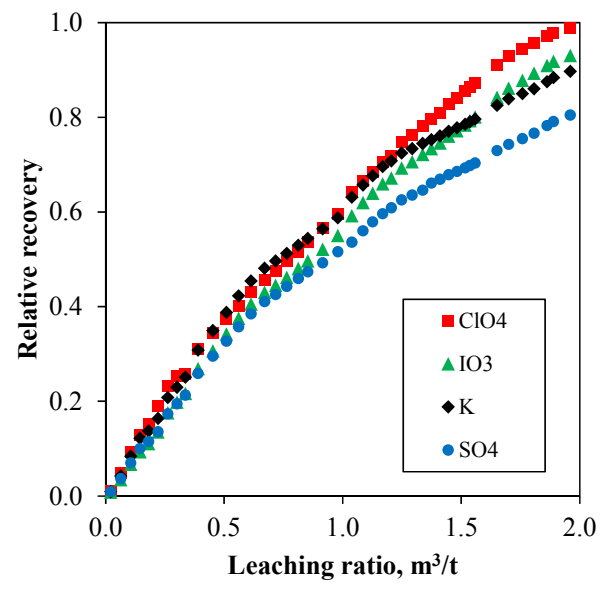

(b) 


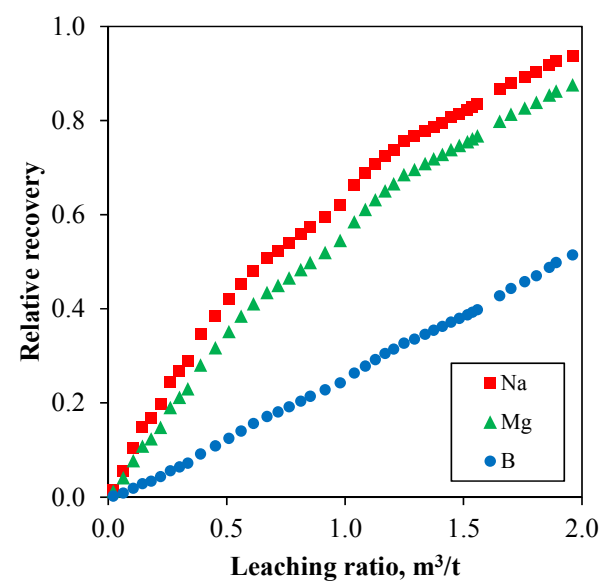

(c)

Figure 5: Recovery curves of ions for large particle column leaching. (a) Nitrate, Chloride and Calcium, (b) Perchlorate, Iodate, Potassium and Sulphate and (c) Sodium, Magnesium and Boron.

The effect of the particle size on recovery was evaluated by comparing the results of coarse leaching (CL experiment) with another leaching experiment previously performed by Ordóñez et al. (2013), in which fine particles, less than $1.4 \mathrm{~cm}$ of diameter, were used with tap water as leaching agent (FL experiment). As shown in Figure 6, the final recoveries of all ions were similar between both experiments. However the increment was slower for the CL experiment; i.e., a larger volume of leaching solution is required to reach the same recovery. The particle size is determinant in this result, because larger particles present higher resistance to inner transport that slows the depleting of ions from caliche. The leachant preferably flowed by the periphery of rocks; however, at the end, all particles were completely wetted and with high levels of water saturation. Some of the particles or part of them collapsed during the leaching. The ratio of leachant volume over mass loaded for the FL experiment was $2.4 \mathrm{~m}^{3} / \mathrm{t}$ (in the recovery figures, the $\mathrm{x}$-axes are presented up to $2.0 \mathrm{~m}^{3} / \mathrm{t}$ because no changes are observed for longer times), while for $\mathrm{CL}$ the leaching ratio was close to $2.0 \mathrm{~m}^{3} / \mathrm{t}$. The last leaching ratio does not consider the fraction of leachant that flowed freely through the glass stones.

\section{Model Results}

The phenomenological model described above was used to simulate data for the coarse leaching experiment. In this simulation the value of the $k$ parameter, which was previously determined by fit- ting the leaching of fine particles (Ordóñez et al., 2013), was used. In that work, the model fitting was done in terms of the outlet concentration of the highly soluble species, and the value obtained was $1.99 * 10^{-5} \mathrm{~m} / \mathrm{h}$. The parameters used in the simulation of the different experiments are listed in Table 7.

Table 7: Parameters used in the simulation of the phenomenological model.

\begin{tabular}{|l|c|c|}
\hline Parameter & $\begin{array}{c}\text { FL } \\
\text { Experiment }\end{array}$ & $\begin{array}{c}\text { CL } \\
\text { Experiment }\end{array}$ \\
\hline Average particle radius, $\mathrm{m}$ & 0.007 & 0.06 \\
Nitrate mass fraction & 0.037 & 0.047 \\
Mass transfer coefficient, $\mathrm{m} / \mathrm{h}$ & $1.99 * 10^{-5}$ & $1.99 * 10^{-5}$ \\
Solubility concentration, $\mathrm{kg} / \mathrm{m}^{3}$ & 230 & 230 \\
Water porosity & 0.08 & 0.08 \\
Column base geometry & Circular & Square \\
Cross section column area, $\mathrm{m}^{2}$ & 0.031 & 0.078 \\
Bed height, $\mathrm{m}$ & 1.0 & 0.6 \\
Irrigation rate, $\mathrm{m}^{3} / \mathrm{m}^{2} / \mathrm{h}$ & 0.006 & $0.004 / 0.002$ \\
\hline
\end{tabular}

The simulated recovery for the FL experiment was determined from the simulated outlet concentration obtained using the fitted $k$ parameter. On the other hand, the recovery for the CL experiment was determined from the outlet concentration simulated using the same $(k)$ parameter obtained in the FL experiment.

It is observed that the model captures the recovery of nitrate for coarse particles. It is appropriate to note the consistency of the model, since no further adjustment was required. This indicates that the $k$ parameter is only slightly dependent on the operating conditions (Figure 7); but is strongly influenced by the species that is being leached. 


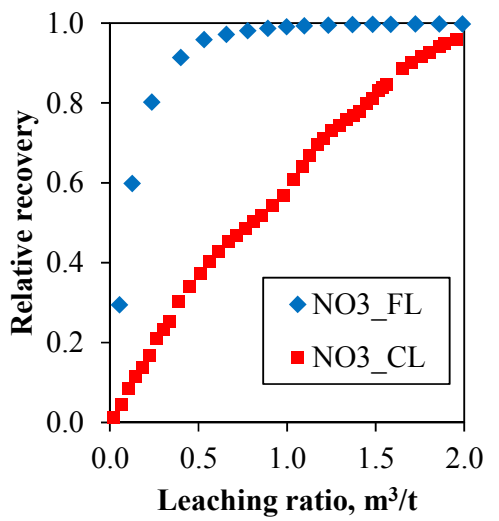

(a)

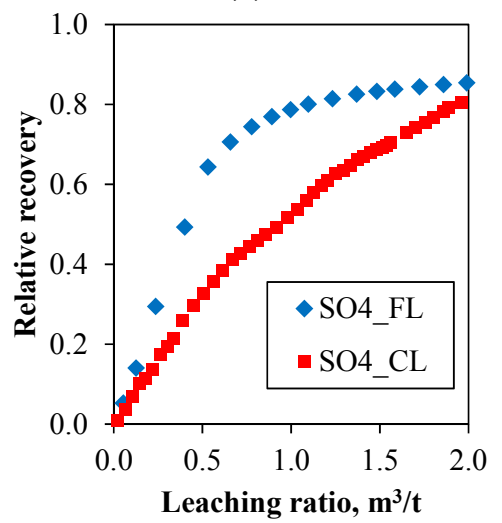

(c)

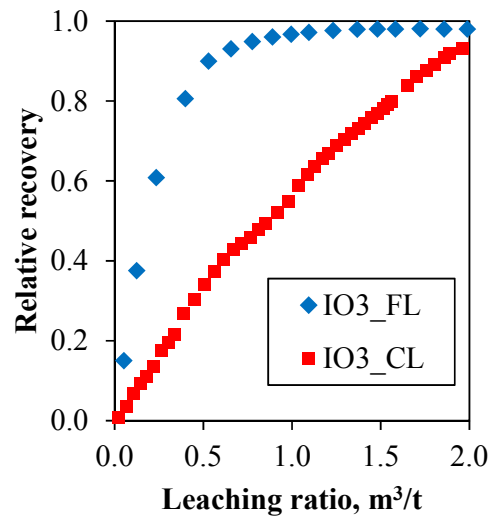

(b)

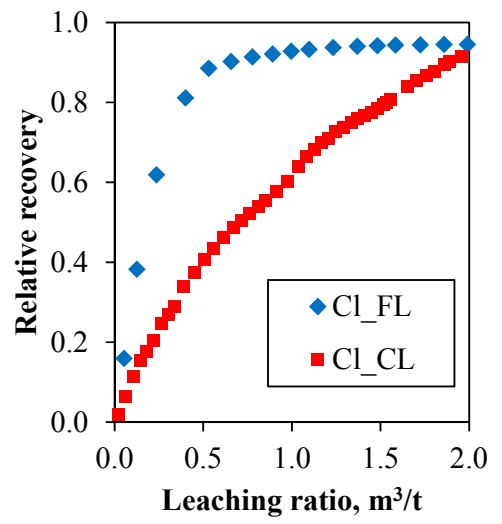

(d)

Figure 6: Comparison of recoveries between column leaching using small and large particles as a function of leaching ratio (volume of leachant/mass of caliche). (a) Nitrate, (b) iodate, (c) sulphate and (d) chloride. FL: Fine particle leaching and CL: Coarse particle leaching.

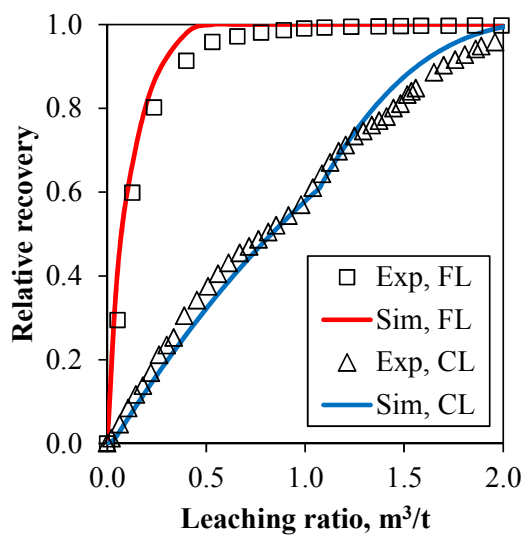

Figure 7: Simulation of nitrate recovery from the phenomenological model for fine $(\mathrm{FL})$ and coarse (CL) leaching experiments. Markers are experimental results and lines correspond to simulated data. 
The recovery of nitrate close to 1.0 was rapidly reached for the FL experiment after only $0.5 \mathrm{~m}^{3} / \mathrm{t}$. While, for the CL experiment this value is not reached even after $2.0 \mathrm{~m}^{3} / \mathrm{t}$. The experiment with coarse particles was simulated using two flowrates; 0.004 and $0.002 \mathrm{~m}^{3} / \mathrm{m}^{2} / \mathrm{h}$. Despite this change in the irrigation rate, the trends were well reproduced.

\section{CONCLUSIONS}

The contribution of this work is threefold: i) new data of column leaching experiments using coarse caliche ore are supplied, ii) a previously developed model is applied to the leaching of coarse particles with an acceptable level of agreement, and iii) determination of physical properties of caliche mineral is carried out.

The leaching experiment showed that dissolution rates using coarse particles were much slower than the rates observed with finer particles, and three types of ions with different dissolution behaviours were observed. High recoveries are obtained even using large particles if the material is irrigated during longer times.

The results of leaching experiment were simulated using the previously developed model for highly soluble species proposed by Gálvez et al. (2012). It was found that the model can be used directly for the representation of the leaching of coarse particles without fitting using the same mass transfer coefficient that was obtained for small particles. A good representation of the recovery for nitrate was obtained from the simulation. This shows that the model is adequate to simulate caliche leaching with different particle sizes. In this sense, it was also demonstrated that the conceptual model is a correct approach; i.e., the leaching takes place on the particle surface and advanced into the particle when the material in the surface is partially dissolved or has collapsed as was assumed in the model.

In the determination of physical properties, it was found that caliche has a high capillarity because the porous structure is formed by very small pores. This also causes caliche to show a very small permeability. Therefore, the leaching solution may be sucked into the caliche ore, but water flow through a caliche ore is negligible or not possible. This clearly indicates that the leaching takes place on the particle surface and an insignificant part of the leaching occurs in the interior.

\section{NOMENCLATURE}

A Cross-sectional area of the reactor $i\left(\mathrm{~m}^{2}\right)$
$C_{i} \quad$ Concentration in the reactor $i\left(\mathrm{~kg} / \mathrm{m}^{3}\right)$

$C_{i-1} \quad$ Concentration in the reactor $i-1\left(\mathrm{~kg} / \mathrm{m}^{3}\right)$

$C_{s} \quad$ Solubility of ion $i\left(\mathrm{~kg} / \mathrm{m}^{3}\right)$

$g \quad$ Gravity $\left(\mathrm{m} / \mathrm{s}^{2}\right)$

$H \quad$ Total height of permeability test (m)

$h_{m} \quad$ Average level of kerosene (m)

$K \quad$ Permeability coefficient $\left(\mathrm{m}^{2}\right)$

$k \quad$ Mass transfer coefficient $(\mathrm{m} / \mathrm{h})$

$k_{c} \quad$ Capillary coefficient $\left(\mathrm{kg} / \mathrm{m}^{2} / \mathrm{h}^{0.5}\right)$

$M_{\text {sat }} \quad$ Mass of saturated caliche sample $(\mathrm{kg})$

$M_{s} \quad$ Initial mass of the caliche sample $(\mathrm{kg})$

$N_{p} \quad$ Number of particles in reactor $i$

$Q \quad$ Flow of kerosene $\left(\mathrm{m}^{3} / \mathrm{s}\right)$

$q \quad$ Irrigation rate $\left(\mathrm{m}^{3} / \mathrm{m}^{2} / \mathrm{h}\right)$

$r_{e} \quad$ Radius of cylindrical caliche sample (m)

$r_{h} \quad$ Radius of internal hole (m)

$r_{i} \quad$ Particle radius in the reactor $i(\mathrm{~m})$

$V_{s} \quad$ Volume of displaced kerosene $\left(\mathrm{m}^{3}\right)$

$V_{w i} \quad$ Volume of water in the reactor $i\left(\mathrm{~m}^{3}\right)$

$t \quad$ Time (h)

$Z \quad$ Height of caliche sample (m)

\section{Greek Letters}

$\alpha \quad$ Mass fraction of soluble species in caliche

$\varepsilon \quad$ Open porosity of caliche

$\rho \quad$ Apparent density of mineral $\left(\mathrm{kg} / \mathrm{m}^{3}\right)$

$\rho_{k} \quad$ Kerosene density $\left(\mathrm{kg} / \mathrm{m}^{3}\right)$

$\mu \quad$ Dynamic viscosity of kerosene $(\mathrm{kg} / \mathrm{m} / \mathrm{s})$

\section{ACKNOWLEDGEMENTS}

The authors thank CONICYT and the Regional Government of Antofagasta by their funding through PAI program, Project Anillo ACT 1201.

\section{REFERENCES}

AENOR, Asociación Española de Normalización y Certificación, UNE-EN 1925, Natural Stone test Method. Determination of Water Absorption Coefficient by Capillarity, p. 13 (1999).

Bennett, C. R., McBride, D., Cross, M., Gebhardt, J. E., A comprehensive model for copper sulphide heap leaching Part 1 Basic formulation and validation through column test simulation. Hydrometallurgy 127, 150-161 (2012). 
Bird R. B., Stewart, W. E., Lightfoot, E. N., Transport Phenomena. Second Ed., John Wiley and Sons, Inc. New Jersey (2002).

Bouffard, S. C., Dixon, D. G., Investigative study into the hydrodynamics of heap leaching processes. Metallurgical and Material Transactions, B 32B, 763-776 (2001).

De Andrade Lima, L. R. P., A mathematical model for isothermal heap and column leaching. Brazilian Journal of Chemical Engineering 21, 435477 (2004).

Dokoumetzidis, A., Macheras, P., A century of dissolution research: From Noyes and Whitney to the Biopharmaceutics Classification Systems. International Journal of Pharmaceutics 321, 1-11 (2006).

Ericksen, G. E., The Chilean nitrate deposits. American Scientist, 71, 366-374 (1983).

Gálvez, E. D., Moreno, L., Mellado, M. E., Ordóñez, J. I., Cisternas, L. A., Heap leaching of Caliche minerals: Phenomenological and analytical models - some comparisons. Minerals Engineering, 33, 46- 53 (2012).
Ghorbani, Y., Becker, M., Mainza, A., Franzidis J., Petersen, J., Large particle effects in chemical/ biochemical heap leach processes - a review. Minerals Engineering, 24, 1172-1184 (2011).

Ordóñez, J. I., Moreno, L., Gálvez, E. D., Cisternas, L. A., Seawater leaching of caliche mineral in column experiments. Hydrometallurgy, 139, 7987 (2013).

Ordóñez, J. I., Moreno, L., Mellado, M. E., Cisternas, L. A., Modeling validation of caliche ore leaching using seawater. International Journal of Mineral Processing, 126, 10-17 (2014).

SQM Webpage, <http://www.sqm.com> (Accessed: August 2013).

USGS, United States Geological Survey Webpage, $<$ http://www.usgs.gov> (Accessed: October 2013).

Valencia, J. A., Méndez, D. A., Cueto, J. Y., Cisternas, L. A., Saltpeter extraction and modelling of caliche mineral heap leaching. Hydrometallurgy, 90, 103-114 (2008).

Wheeler, A., Technical Report on the Aguas Blancas Property, Chile. Internal Report, 1-57 (2010). 